\title{
On Piano Teaching with the Aid of Classical Chinese Poems: A Case Study on Chopin's Etude OP 10, No 3
}

\author{
Mingchun $\mathrm{Li}^{1}$ \\ ${ }^{1}$ College of Music, Southwest University, Chongqing, China \\ Correspondence: Mingchun Li, College of Music, Southwest University, Beibei, Chongqing, China. Tel: \\ 86-136-3838-2281. E-mail: mingchun.lee@hotmail.com
}

Received: August 15, 2013 Accepted: September 17, 2014 Online Published: September 29, 2014

doi:10.5539/ass.v10n19p263 URL: http://dx.doi.org/10.5539/ass.v10n19p263

\begin{abstract}
Chopin, a great composer and piano player of the Romantic period, holds a unique and irreplaceable position in the history of Western piano. His piano compositions are well known for their poetic and musical structures, cantabile melodies and tones, ingeniously harmonious language, and profound national emotions. These features are highly similar to classical Chinese poems in terms of structure, rhythm, emotion, and musicality. For Chinese people, their acceptance and love of Western music are largely begun with their appreciation of Chopin's piano works. Interpreting Chopin's music by classical Chinese poems is therefore conducive to further grasping the essence of his works. This paper attempts to focus on Chopin's etude Op10, No3 to demonstrate the charm of his music from the traditional cultural perspective of classical Chinese poems and, by a detailed analysis of his masterly rhythm and poetic structure of music, to reveal how such a perspective can help achieve the purpose of piano teaching.
\end{abstract}

Keywords: classical Chinese poetry, cultural comparison, Chopin's music, piano teaching

\section{Introduction}

Chopin (1810-1849) is a famous Polish composer, pianist and 'patriotic musician' of the Romantic era, who has been renowned as a 'poet of piano'. Since he left his motherland at the age of 20, he is conventionally referred to by some people as a 'voluntary exile'; and as he died in 1849 in Paris, he is also called by others a 'Polish orphan'. He has left behind him over 200 piano compositions including ballades, etudes, preludes, waltzes, and nocturnes. His music is full of elegance, gracefulness, implication, and tenderness, with a distinctive national style and profound patriotism. Anyone who listens to his music would be strongly impressed with the plangent, touching, dreamy and poetic melody and at the same time be shocked by the deepest sorrow, dignified thoughts and brave fights beneath the music. To Robert Schumannh, Chopin's music is a 'cannon concealed amid blossoms', a comment that most vividly and precisely describes its characteristics (She, 2009, p. 112).

Chopin's music is a combination of poetic musical structures, cantabile melodies, and ingeniously harmonious languages, able to produce distinctive and unique musical features in both their details and general features including their contents, emotions, images and artistic conceptions (Zheng, 2010, p. 128). All these have wonderfully similar to classical Chinese poems. This paper attempts to focus on Chopin's etude Op10, No3 to demonstrate the charm of his music from the traditional cultural perspective of classical Chinese poems, and to reveal how this perspective can help achieve the purpose of piano teaching.

\section{The Novelty of Ingenious Rhythms}

Rhythm is originally a musical term, however it is also used in the realm of poetry, so that 'we often call the regular pattern of language as the rhythm of poetry' (Xu, 2007, p. 104).

\subsection{Symmetrical Rhythm}

In this etude, bar lines 38-41 is a series of demiquavers that are completely identical (see music score 1) leading to a symmetrical rhythm which includes the regular repetition of downbeats and upbeats: p---cresc---sf. Such symmetrical rhythm also abounds in classical Chinese poems. A case in point is Fallen Leaves (《落叶》) by Kong Shao'an (577-622) of the Tang Dynasty, whose rhythm is 早秋/惊/落叶, 飘零/似/客心。翻飞/未/肯下, 犹言/忆/故林。(In early autumn leaves fall to my surprise; /Adrift just like the state of a wanderer's heart. /They turn and fly, unwilling to meet their demise; /As though saying, "From our home forest we won't part"). This 
original rhythm of the poem, or its 212 type of pauses, is a logical division, moving from 早秋 (in early autumn leaves) via 惊(to my surprise) to 落叶 (leaves fall) in the first line, and from 飘零 (adrift) via 似 (just like) to 客心 (the state of a wanderer's heart) in the second. Such a poetic structure corresponds and reinforces each other, bringing a stronger expression of the poet's homesickness. The symmetrical rhythm in Chopin's etude also corresponds and reinforces each other, revealing a deeper emotion of the composer otherwise unattainable.

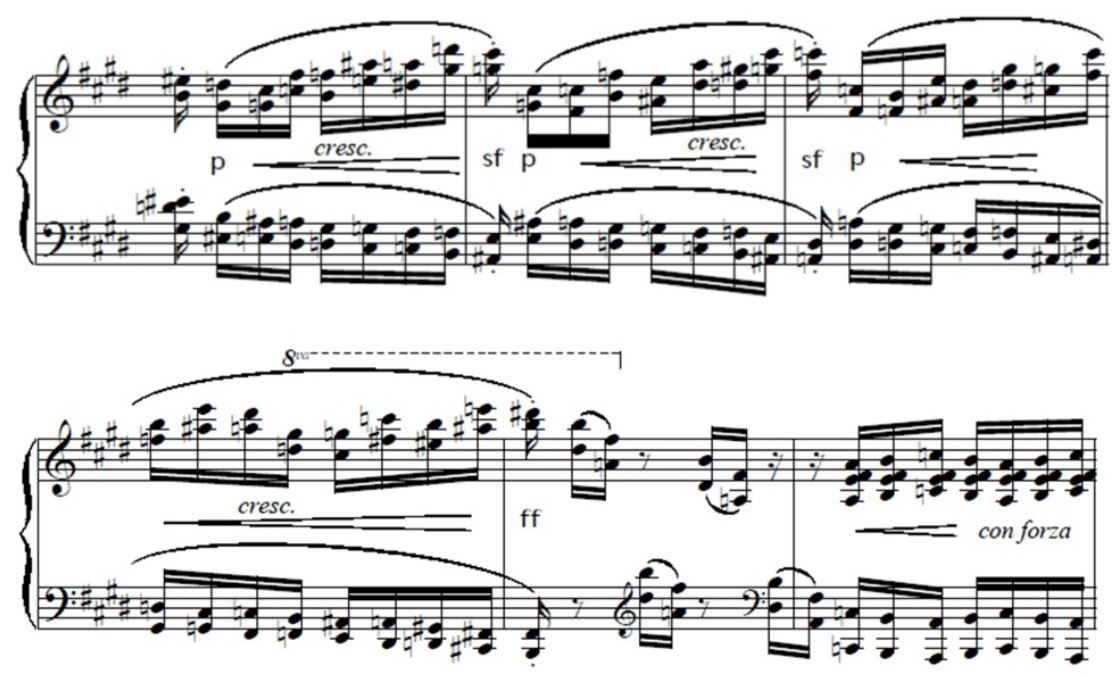

Figure 1. Music score 1

\subsection{Asymmetric Rhythm}

In bars 55, 57, 58, and 59 of the etude, we find an asymmetric rhythm with triplet plays in the left hand and two semiquavers in the right hand (see music score 2), which is deliberately used to reduce the tempo and increase the tune. This not only adds smooth to music but also presents a different sort of aesthetics. Asymmetric rhythm is found in classical Chinese poems as well, as in Li Yu (937-978) whose Everlasting Longing (《长相思》) reads 一重山, 两重山, 山远/天高/烟水寒, 相思/枫叶丹。鞠花开, 鞠花残, 塞雁/高飞/人未还, 一帘/风月闲. (Hill upon hill, rill upon rill; they stretch as far as sky and misty water spread; /My longing lasts till maple leaves grow red. /Now chrysanthemums blow; /Now chrysanthemums go. /You are not back with high-flying wild geese; /Only the moonlit screen waves in the breeze and in moonlight with ease). The rhythms of 山远/天高/烟 水寒, 相思/枫叶丹。鞠花开, 鞠花残, 塞雁/高飞/人未还, 一帘/风月闲 are 2-2-3 and 2-3 caesura. In the first line from 'they stretch as far as sky and misty water spread' to 'my longing lasts till maple leaves grow red', the range upon range of hills are as if the layer upon layer of the everlasting longing and the boundlessly stretching sky and hills are comparable to the limitlessness and endlessness of the feelings; the spreading misty water is just as cold as the yearning heart of the poet. Immediately after all these follow 一宋/风月闲 (only the moonlit screen waves in the breeze and in moonlight with ease) to expose the boundless and incessant yearning of the poet for his hometown. From tempos 2-2-3 to 2-3, the language and emotion are suddenly ceased, but the reader is left to ponder the profound significance behind the words. This type of rhythm is very similar to "triplet with two semiquaver" in music. What underlies the asymmetric rhythm in Chopin's work is the unspeakable missing feelings and sorrows of homesickness and separation.

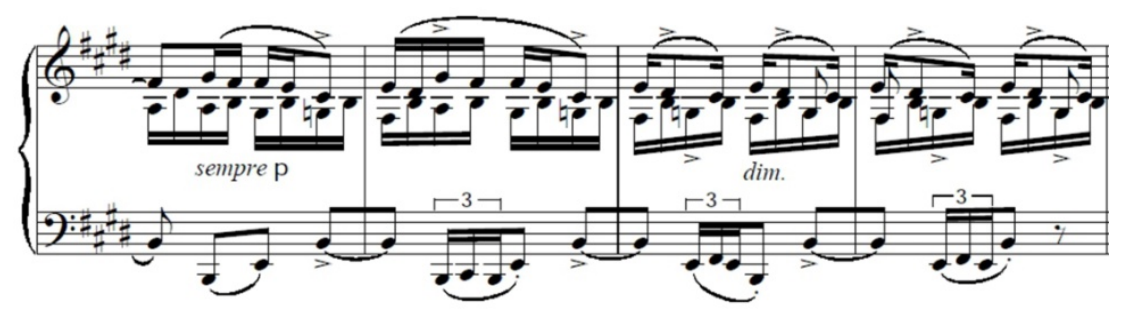

Figure 2. Music score 2 


\subsection{Free Rhythm of Tempo Rubato}

A unique feature of Chopin's music is its tempo rubato which, according to Franz Liszt, is 'a covert, intermittent speed; a soft, free, abrupt and lazy rhythm. It is volatile like a fire stimulated by the air, a waving field where the wheat flows with the breeze, and a treetop swinging in a blast of sharp wind. It is a free tune as smooth as the rhythms of life and thoughts rather than a broken tempo. Another mistake is to render the tempo lifeless and flat' (Fu, 2002, p. 307).

Poems also have free rhythms that function not as semantic or logic pauses but as emotional rhythms. An random example is Chen Zi'ang (659-700) whose Song on Climbing Youzhou Terrace (《登幽州台歌》) reads 前不见古人, 后不见来者。念天地之悠悠, 独怆然而涕下。(Behind me I do not see the ancient men, before me I do not see the ones to come. Thinking of the endlessness of heaven and earth, alone in despair, my tears fall down). Different readers with diverse emotional experience might have different understandings of and feelings about this poem, which is contributed by the space that its tempo rubato allows for a greater freedom in reading and interpretation. The last two lines can be interpreted emotionally with a 1-3-2 rhythm as 念/天地之/悠悠, 独/怆然而/涕下, or with a 3-1-2 rhythm as 念天地/之/悠悠, 独怆然/而/涕下. Therefore one can adopt different speed and dynamics within a proper scope to interpret the poem for its various emotions and rhythms in accordance with certain surroundings and feelings. The tempo rubato can endow a poem with more space and emotion which, in turn, poses great difficulties in teaching. With such poems, it might be a help if we compare the tempo rubato in music and adopt rhythmic variations our teaching process.

So is with this piece of Chopin's etude. Take its theme for example. We may begin it softly with upbeats at a constant speed; when the sound gradually increases and emotion intensifies, we can play it lightly faster until it almost reaches the highest note, or the $\mathrm{C}$ note in the third bar, when the sound is widened both as an emphasis and the climax of emotion. After this emphasis and with the falling of the pitch, we may weaken our power to decrease the rhythm and to return the speed to the beginning. (see music score 3 )

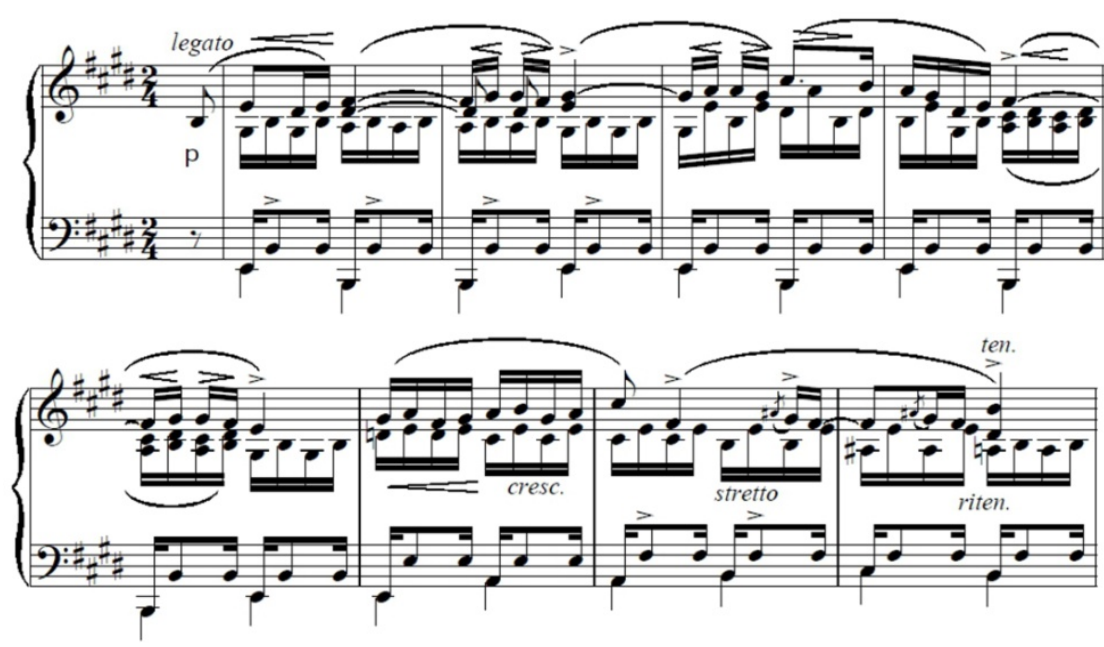

Figure 3. Music score 3

\section{Poetic Musical Structure}

\subsection{Introduction, Taking-Up, Transition and Conclusion as Structure of Poetry and Music}

The theme part of this piece of Chopin's etude is romantically lyrical. Structurally, it moves from introduction (the first two bars) to taking-up (the third bar) to transition (the forth bar) to conclusion (the fifth bar), a four ingredient structure that fully demonstrates the beauty of tension with such downbeats and upbeats. What do these “four ingredients"一起(introduction), 承(taking-up), 转(transition), 合(conclusion) - mean? The “four ingredient structure" is one of the common methods adopted in the composition of regulated classical Chinese verses. According to An Essay in Literary Aesthetics by Liu Xizai (1813-1881), a scholar of the Qing Dynasty, 起 means the beginning and 合 means the conclusion, yet they are both included within and corresponding to each other, with 承 and 转 in between that are able to move both ways (You, 2011, p. 30). In other words, the four ingredients are inter-related, inter-dependent and strict in logic. 
The method of the 'four ingredients' is not limited to classical Chinese poetry only, it is also extensively employed in music composition. To illustrate, we can compare Crossing the Han River (《渡汉江》) by Song Zhiwen (656-712) and Chopin's etude in discussion. Song's poem goes: 'Beyond the mountain there came no tidings and letters; Winter passed, and then went Spring. As I near my village my heart grows more afraid, And I dare not inquire of those that come to meet me.' First of all, the poem begins with 'Beyond the mountain there came no tidings and letters'. Such a beginning functions as the 'introduction' to the sorrow of the poet, which is quite similar to the beginning of Chopin's composition in which the pianist was also impressed by sensitive matters like a sliver cup from a confident or a handful of soil from his hometown that can easily bring about his melancholy. Secondly, in the 'taking-up', or 'Winter passed, and then went Spring', the poet's homesickness is further intensified through his sense of time, while in the Chopin's etude the emotion reaches its climax through an expansive space of thinking delivered by the tune. The third line of the poem 'As I near my village my heart grows more afraid' acts as a transition, and the same role is played in the 4th bar of Chopin's etude to express emotions. Finally, in the 'conclusion' the poem goes 'And I dare not inquire of those that come to meet me' which vividly describes the poet's ambivalence of his eager to receive home letters and of his fear of having his family to get involved into his own troubles, leaving profound implications to the readers. Similarly, the 5th bar of Chopin's etude croons the composer's deep feelings, even when the tune is ceased, the everlasting meanings continues to flow in the listeners' minds. (see music score 3 )

\subsection{Palindrome and Repetition as Delight in Poetry and Music}

The 14 and 15 bars of the etude(see music score 4) conveys sentiment and melancholy to people's ears and hearts with palindrome and repetition 回文反复. Palindrome literally means palindrome and repetition, two rhetorical devices in the composition of classical Chinese poems.

A palindrome can be a word, a phrase, a number, or any other sequence of symbols or elements that reads the same forward or reversed, such as 'madam' or ' 1234321 '. Palindrome poem is one form of classical Chinese poetry. Legend goes that Fu Xian (239-294) and Wen Qiao (288-329) used to write such poems. Record shows that a talented woman named Su Hui (357-?) has left us a brocaded stitchwork she did as a gift to her husband when he was away from her. This stitchwork contains 840 plangent characters that can go both forward and reversed. In the west, the crab canon in music is similar to a Chinese palindrome poem. This musical technique was first used in Clausula in the $13^{\text {th }}$ century, and most of the canon music in the $14^{\text {th }}$ and $15^{\text {th }}$ centuries were crab canon which is interpreted as "the end is my beginning" by the famous French composer Guillaume de Machaut (Qian, 2003, p. 546). Palindrome is easily found in many classical Chinese poems, such as Song of the Country Norm (《菩萨蛮》) by Zhang Xiaoxiang (1132-1169) of the Southern Song Dynasty: 渚莲红乱风翻雨。 雨翻风乱红莲渚。深处宿幽离。禽幽宿处深。淡妆秋水鉴。鉴水秋妆淡。明月思人情。情人思月明。Every two lines of the poem make up a unified theme wherein each line is a palindrome of the other, so that the words read exactly the same no matter we read them forward or backward. It must be noted that the poet did not create a new form intentionally; rather he deliberately followed a tradition and painted the lotus pond in rain and wind to gradually draw out the subtle sorrow of his longing for his beloved when he saw the moon after the rain. Likely, the palindrome form used in Chopin's etude is also conducive to the expression of his emotion. The line “明月思人情。情人思月明。' is rhythmically comparable to the stanzaic repetition of the upbeat part in the etude. To describe in this way is to help the students understand that the form is aimed not at the novelty of forms but at the content and emotion within the music.

Repetition is a purposeful restatement of a word or sentence such as the AABB form. A repetition or restatement in music is determined by artistic rules and aesthetic principles. According to Schopenhauer in his The World as Will and Presentation, 'replication and repetition help us see how rich and meaningful the content and the musical language are. Though they are intolerable in prose, they are comfortable and advantageous in music, because to understand the music well, we need to listen twice' (Qian, 2003, p. 502). Repetition, therefore, can greatly strengthen the artistic expression of a musical work. In poems, repetition is also a significant rhetorical device 'to express thoughts and emotions by repeating a certain word or sentence '. To interpret the repetition in music through the repetition in poems can make the emotion more delicate and complementary, as is illustrated in Song of Ugly Slave (《丑奴儿》) by Xin Qiji (1140-1207) : 少年不识愁滋味, 爱上层楼。爱上层楼, 为赋 新词强说愁。而今识尽愁滋味, 欲说还休。欲说还休, 却道天凉好个秋! (While young, I knew no grief I could not bear; I'd like to go upstair. I'd like to go upstair to write new verses with a false despair. I know what grief is now that I am old; I would not have it told. I would not have it told, But only say I'm glad that autumn's cold.) This poem reveals the transformation of two contrasting sentiments by setting off the unspeakable grief of today against the past when the speaker knew nothing about sorrow. 'I'd like to go upstair' is repeated to emphasize the social inexperience and innocence of the speaker, and 'I would not have it told' is repeated to 
reinforce the speaker's deep depression from his inability to release his sorrow. In Chopin's etude, repetition aims to emphasize personal feelings as well. Restatement can also be found in other parts of the etude such as from 58 to 61 bars where the same musical materials are repeated four times, or at the end of the B segment in which not only the feeling of separation is going to be enhanced but also the dynamics and tempo will be gradually softened and slowed down. Even though the notes and harmonies are unchanged, but the emotions expressed do have some changes (see music score 5). It reveals the composer's painful feelings of saying farewells to his beloved ones.

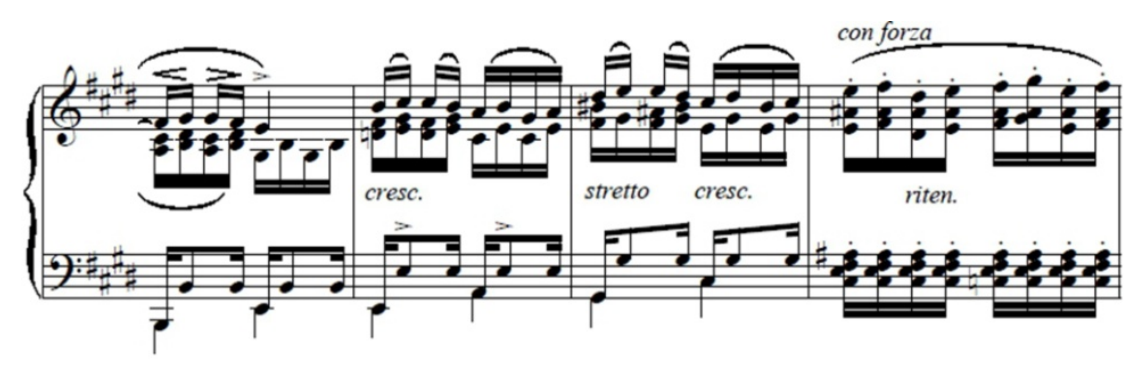

Figure 4. Music score 4

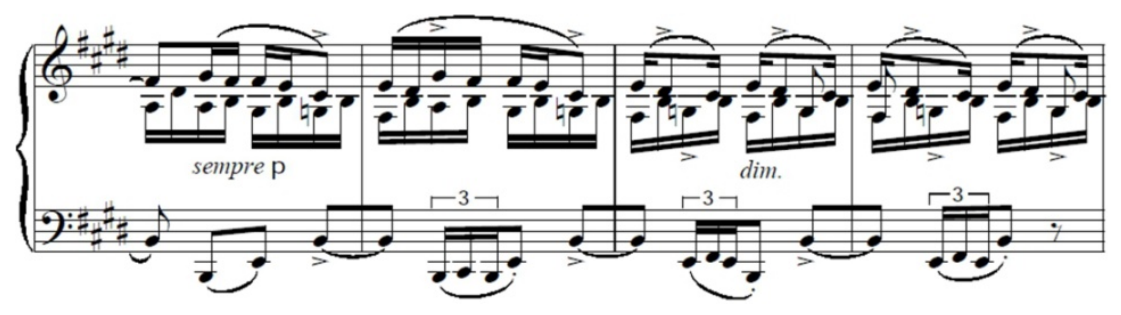

Figure 5. Music score 5

\section{3 'Sequence-parallel' as Rhythm in Poetry and Music}

A sequence, also call 'shift' in music, is the immediate restatement of a motif or a longer melodic (or harmonic) passage at a higher or lower pitch in the same voice. In bars 14 and 15 bars of the Chopin's etude (see music score 6), the same materials have different pitches, just like identical containers with different matters. This method not only gives the music better appeal but also gradually deepens the sentiment within. A sequence in music is comparable to parallelism in poetry. In rhetoric, parallelism refers to phrases, sentences or paragraphs that are basically the same in structure and used in accordance with certain order. It is among the most important rhetorical devices to make poems have their distinctive rhythms (Xu, 2007, p. 176). Many poems in The Book of Songs show a kind of device called 'repetition of lines', an example being the first three sections in Caiwei, Lesser Elegancy in Book of Poetry (小雅·采薇): 'Let us gather the thorn-ferns, let us gather the thorn-ferns; The thorn-ferns are now springing up. When shall we return? When shall we return? It will be late in the [next] year. Wife and husband will be separated, Because of the Xian-yun. We shall have no leisure to rest, Because of the Xian-yun. Let us gather the thorn-ferns, let us gather the thorn-ferns; The thorn-ferns are now tender. When shall we return? When shall we return? Our hearts are sorrowful; Our hearts are sad and sorrowful; We shall hunger, we shall thirst. While our service on guard is not finished, We can send no one home to enquire about our families. Let us gather the thorn-ferns, let us gather the thorn-ferns; The thorn-ferns are now hard. When shall we return? When shall we return? The year will be in the tenth month. But the king's business must not be slackly performed; We shall have no leisure to rest. Our sorrowing hearts are in great distress; But we shall not return from our expedition.' The poem is about the feelings and thoughts of a garrison soldier suffering from extreme pain of homesickness and is returned from the borderland. It narrows his arduous life in the frontier, his enthusiasm and love for his country and family, as well as his worries for current affairs. The three sections here quoted is a flashback of the plight he has been through during all those campaigns. The soldier-speaker spent a long time away from his family for battles. Army life was so tough that the he and his fellow-soldiers had to put up with frequent shifts of grounds, ceaseless royal business, little time to rest, and sometimes even the gathering of thorn-ferns for food. It is hard for the speaker to hide his complaint against a sea of difficulties and his yearning for returning home. By using parallelism, the three structurally similar sections keep the differences 
from each other and step by step enhance the speaker's feelings. Parallelism in poetry is highly similar to the sequence in Chopin's etude. Because of the singability of the poems in The Book of Songs, we can improve our teaching by using Chopin's etude as a background music and the poems as a lyrics to explain the nature of the sequence technique.

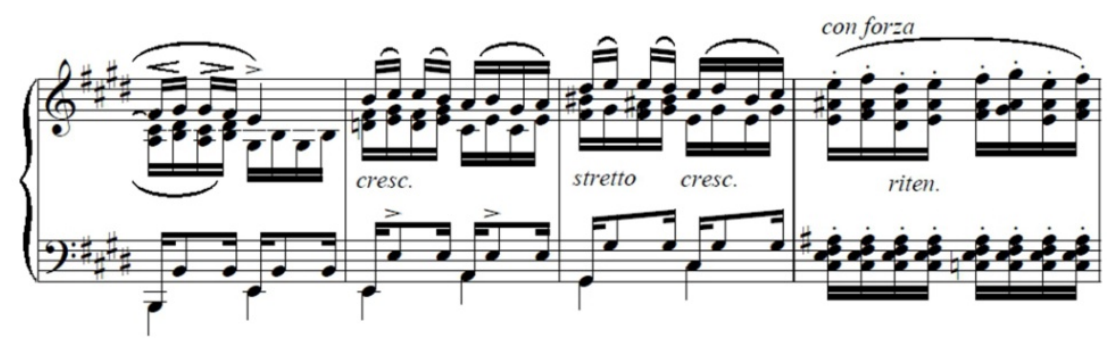

Figure 6. Music score 6

\subsection{Image Superposition and Reduplication as Taste in Poetry and Music}

In Chopin's etude Op10, No3, the thematic melody is composed of three voice parts: its high pitch sounds like a violin playing on an open line, its bass like a contrabass playing on a dark line running through an offbeat melody, and its medium strengthens the harmonies to produce a more full sound.

Image superposition means several images put together, also called 'composition of images' in poetry. Fan Ye (398-455) of the Southern Dynasty wrote in his Letter to my Nephews Written in Prison (《狱中与诸特侄书》) : 'I usually consider writing as a means to express emotions, emphasize the meaning, present the theme, and convey them the reader. There should be no miscommunication' (Xu, 2007, p. 268). Therefore the composition of images means to put the focus on the significance or 'to choose images that can best embody the meaning' (Xu, 2007, p. 269) before all the chosen images are put together for 'an organic whole' (Xu, 2007, p. 271). The superposition of the three voice parts of Chopin's etude is just like the image composition in classical Chinese poetry, with each part expressing its own distinctive meaning yet interweaving together to form an organic whole Take Tune: Thinking in Autumn (《天净沙.秋思》) by Ma Zhiyuan (1264-1321?). The poem reads 'Withered vines hanging on old branches, /Returning crows croaking at dusk. /A few houses hidden past a narrow bridge, /And below the bridge a quiet creek running. /Down a worn path, in the west wind, /A lean horse comes plodding. /The sun dips down in the west, /And the lovesick traveler is still at the end of the world.' Because a poem has to be presented in a liner structure which is different from music, so such images as 'withered vines', 'returning crows', 'narrow bridge', 'quiet creek', 'worn path', and the '(dipping) sun' must appear one after another, but at the same time they are interconnected for a certain significance. A 'worn path' refers to the place where friends part each other in ancient times and 'withered vines' indicate a feeling of dreariness. Modifiers like 'withered', 'returning', and 'lean' add sentiments to infinite loneliness and anguish against the sad scenery of Autumn. These images trigger the innermost sorrow of the 'lovesick traveler' 'at the end of the world', echoing and interweaving strong emotions, creating a wonderful poetic world through the combination of images and feelings. In Chopin's etude, the three voice parts enhance each other and produce the dimensions and layers of the music, in which the high-pitch portrays the melancholy and sorrow of the composer, echoed by the deeply low harmonies of the bass to enrich homesickness and filled by the harmonies of the medium part to strengthen the sound. The difference between poetry and music does not prevent the share of superposition device to create similar effects.

Besides, the superposition of the notes in the etude is similar to reduplication in classical Chinese poetry. Bars 30 and 31, for example, contain 4 superpositions of two notes in the medium voice part which is used to reveal the inner feelings of the composer. This use of superposition in music is exactly the same as the reduplication in classical poems, as is illustrated by the following lines from Song for White Hair(《代悲白头翁》) by Liu Xiyi (651-679): 年年岁岁花相似, 岁岁年年人不同 (Next year when the flowers bloom, who will still be here?). Here, the reduplicated words 年年 and 岁岁 painfully reveal the fact that time flies and people change, a fact that, because of the use of reduplication, also reveals the poet's hopelessness, sorrow, panic, and solitude. The use of reduplication in poems can fasten and sharpen the moderate and pathetic rhythms, enhancing the painfulness of the speaker, which again is identical in Chopin's etude. Forced to live away from his country, Chopin was constantly tortured by strong longings for his motherland and family. Through poems that have the same implication with Chopin's etude, we can help students develop a more profound understanding of the composers' 
emotions; and through a familiar context of traditional culture, we can also help student better recognize the emotional patterns in the western music.

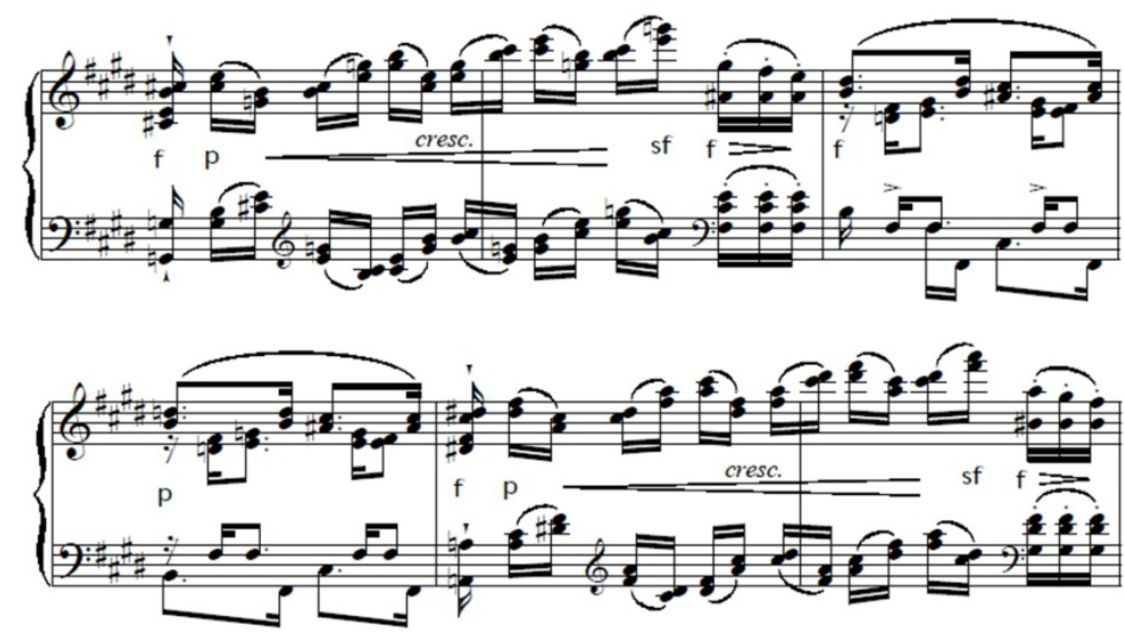

Figure 7. Music score 7

\section{Conclusion}

Poems are said to have developed from songs that ancient people sang to reduce their fatigue when working. They used to serve as an expressive form of emotional communication and before they became lyrics accompanied with music. Both in China and in the west, poetry and music have been closely connected since ancient times. They enjoy the common feature of serving as a kind of language that is full of tempos and rhythms, able to truly reflect social lives, to express emotions, and to present the artistic conceptions of the authors.

By comparing classical Chinese poems with Chopin's musical work, we can find several similarities. First of all, the rhythms in Chopin's music are able to reflect the artistic process from 'reality' via 'expression' to 'sentiment', a process which is similar to the process in poetry. Secondly, the poetic rhythms in the etude can also present rich artistic images to inspire infinite imagination of the listeners. Thirdly, musical notes as one of the artistic mediums can help integrate music and poetry into a state of harmony.

Teachers of music need to improve their cultural awareness in classical Chinese poetry by using the similarities of the two artistic forms to acquire a deeper understanding and interpretation of music. Students majoring in music should not merely focus on the study of western music, but need to improve their artistic cultivations in other aspects as well, including the history of western art and classical Chinese literature. This is especially true when dealing with music like Chopin's that has a lot in common with classical Chinese poetry, such as writing techniques, rhythms and emotional expressions. To be able to teach piano and appreciate Chopin's music with the help of classical Chinese poetry shall be conducive to Chinese piano players who hope to step into the innermost of him, to appreciate the charm of his music, and to provide music admirers with a special artistic experience.

\section{Acknowledgements}

This paper is supported by the Fundamental Research Funds for the Central Universities, NO. SWU1109047.

\section{References}

Fu, L. (2002). About music. Changsha: Hunan Culture \& Art Press.

Liang, Y. Q., \& He, Q. F. (1999). Love for music-CD classics. Hangzhou: Zhejiang People's Press.

Liszt, F. (1978). Life of Chopin. trans. Zhang, Z. M., Gao, S. Y. ,Yu, C. Z., \& Guo, Y. Beijing: People's Press of Music.

Qian, R. K. (2003). Selected essays on music. Shanghai: Shanghai Music Press.

Ren, B. Y. (1984). A General Introduction to Poetry. Shenyang: Liaoning People's Press

Shang, T., Ding, Q., Ma, L., \& Wang, L .L. (2012). Architecture and music. Wuhan: Wuhan University Press.

She, T. (2009). The story of art. Changchun: Northern Women and Children's Press. 
Xu, Y. F. (2007). Poetics theories. Beijing: Peking University Press.

You, J. B. (2011). Contemporary music education series: A Coursebook for writing popular songs. Beijing: Popular Culture \& Art Press.

Zhen, Y. (2012). The meaning and methods of expression of basic musical elements in piano playing. Journal of Hainan Normal University (Social Sciences), 128-131. http://dx.doi.org/10.3969/j.issn.1674-5310.2010.04. 026

\section{Copyrights}

Copyright for this article is retained by the author(s), with first publication rights granted to the journal.

This is an open-access article distributed under the terms and conditions of the Creative Commons Attribution license (http://creativecommons.org/licenses/by/3.0/). 